\title{
Primary and secondary $\mathrm{CoQ}_{10}$ deficiencies in humans
}

\author{
Catarina M. Quinzii and Michio Hirano* \\ Department of Neurology, Columbia University Medical Center, New York, NY, USA
}

\begin{abstract}
$\mathrm{CoQ}_{10}$ deficiencies are clinically and genetically heterogeneous. This syndrome has been associated with five major clinical phenotypes: (1) encephalomyopathy, (2) severe infantile multisystemic disease, (3) cerebellar ataxia, (4) isolated myopathy, and (5) nephrotic syndrome. In a few patients, pathogenic mutations have been identified in genes involved in the biosynthesis of $\mathrm{CoQ}_{10}$ (primary $\mathrm{CoQ}_{10}$ deficiencies) or in genes not directly related to $\mathrm{CoQ}_{10}$ biosynthesis (secondary $\mathrm{CoQ}_{10}$ deficiencies). Respiratory chain defects, ROS production, and apoptosis variably contribute to the pathogenesis of primary $\mathrm{CoQ}_{10}$ deficiencies.
\end{abstract}

\section{Keywords}

coenzyme $\mathrm{Q}_{10}$; respiratory chain activity; ROS; oxidative stress

\section{Introduction}

Human $\mathrm{CoQ}_{10}$ deficiencies are clinically and genetically heterogeneous diseases. In most cases, family history suggests an autosomal recessive mode of inheritance. In 18 patients, pathogenic mutations in genes encoding for proteins involved in the biosynthesis of $\mathrm{CoQ}_{10}$ have been identified (primary $\mathrm{CoQ}_{10}$ deficiencies) [1-7].

\section{Primary $\mathrm{CoQ}_{10}$ deficiencies}

In 1989, Ogasahara et al. first described patients with $\mathrm{CoQ}_{10}$ deficiency, two sisters who presented with mitochondrial myopathy, elevated serum creatine kinase (CK), recurrent myoglobinuria, lactic acidosis, seizures, and mental retardation, associated with decreased activities of complexes I + III and II + III and markedly reduced $\mathrm{CoQ}_{10}$ in muscle [8]. Since then, several patients with encephalomyopathy manifesting the same clinical triad of mitochondrial myopathy, recurrent myoglobinuria, and encephalopathy have been reported to have $\mathrm{CoQ}_{10}$ deficiency [9-12]. In these patients, treatment with $\mathrm{CoQ}_{10}$ supplementation improved mainly the muscle symptoms, and the molecular defect, compound heterozygous mutations in $A D C K 3 / C A B C 1$, has been found only in the patient reported by Aure $[6,12]$.

In 2000, Rötig et al. described for the first time an infantile-onset disorder associated with widespread $\mathrm{CoQ}_{10}$ deficiency in three siblings who presented soon after birth with neurological symptoms, including nystagmus, optic atrophy, sensorineural hearing loss, ataxia, dystonia, weakness, and rapidly progressive nephropathy. The causative mutation in this family has not been reported; however, most of the patients with multisystemic infantile and $\mathrm{CoQ}_{10}$ deficiency described so far have had genetically confirmed primary $\mathrm{CoQ}_{10}$

(C) 2011 International Union of Biochemistry and Molecular Biology, Inc.

*Address for correspondence: Dr. Michio Hirano, MD, Department of Neurology, Columbia University Medical Center, 630 West 168th Street, P\&S 4-423, New York, NY 10032, USA. mh29@ columbia.edu. 
deficiency. In 2006, we reported two siblings, who shared a homozygous missense mutation in the COQ2 gene encoding para-hydroxybenzoate-polyprenyl transferase [2]. The proband was a 33-month-old boy who was noted to have nystagmus at 2 months. At 12 months, he was hospitalized because of a severe nephrotic syndrome and neurological examination showed hypotonia and mild psychomotor delay. At 18 months, he developed frequent vomiting, psychomotor regression, tremor, weakness, hypotonia, and status epilepticus. Brain MRI showed cerebral and cerebellar atrophy and stroke-like lesions. He received a successful renal transplant at 3 years of age. His sister developed nephrotic syndrome at 12 months of age without any clinical signs of neurological involvement $[3,13]$. Both the siblings improved with $\mathrm{CoQ}_{10}$ supplementation $[3,14]$. Rötig and coworkers subsequently reported two siblings harboring a homozygous base-pair deletion in exon 7 of the COQ2 gene. The girl had neonatal neurologic distress, nephrotic syndrome, hepatopathy, pancytopenia, diabetes, seizures, and lactic acidosis progressing to fatal multiorgan failure at age 12 days [4]. The older brother also had anemia, liver failure, and renal insufficiency and died at the age of 1 day.

In 2007, other two patients with early-onset glomerulopathy due to mutations in the COQ2 gene were described [3]. The first patient presented with steroid-resistant nephrotic syndrome at age 18 months as a result of collapsing glomerulopathy, without extra-renal manifestations. The second patient presented at 5 days of life with oliguria had severe extracapillary proliferation on renal biopsy, rapidly developed end-stage renal disease, and died at the age of 6 months after a course complicated by progressive epileptic encephalopathy. Combined complex II + III activity and $\mathrm{CoQ}_{10}$ level were decreased in renal cortex as well as in skeletal muscle.

Mutations in PDSS2 that encodes one of the two subunits of polyprenyl diphosphate synthase, the first enzyme of the $\mathrm{CoQ}_{10}$ biosynthetic pathway, have been reported in a male infant with nephrotic syndrome and Leigh syndrome [1]. The boy presented with neonatal pneumonia and hypotonia. At the age of 3 months, he developed seizures and subsequently became progressively floppy, had difficulty in feeding, had severe episodic vomiting and lactic acidosis, and died at age 8 months due to severe refractory focal status epilepticus. In a consanguineous family, two siblings had $\mathrm{CoQ}_{10}$ deficiency due to a homozygous PDSS1 mutation manifesting as a multisystem disease with early-onset deafness, encephaloneuropathy, obesity, livedo reticularis, and cardiac valvulopathy [6].

In 2009, Duncan et al. reported mutations in another gene, $\operatorname{COQ} 9$, required for the biosynthesis of $\mathrm{CoQ}_{10}$ in a newborn with generalized limb hypertonia, reduced truncal tone, lactic acidosis, renal tubulopathy, and cardiopathy [7]. Brain MRI revealed cerebral and cerebellar atrophy. He developed severe seizures and dystonia and died at 2 years of age.

$\mathrm{CoQ}_{10}$ deficiency in fibroblasts and early renal involvement seem to be a hallmark of primary infantile multisystemic syndromes [1-4,7]. Early supplementation in patients with $C O Q 2$ mutations appears to have alleviated the nephropathy and may prevent development of neurological signs and symptoms [14]. In contrast, the patients with PDSS2 and COQ9 mutations described by Lopez et al. and Rahman et al. died despite $\mathrm{CoQ}_{10}$ replacement.

In 2003, Leshinsky-Silver et al. reported a patient who presented with neonatal liver disease, pancreatic insufficiency, tyrosinemia, hyperammonemia, subsequent sensorineural hearing loss, and Leigh syndrome. Liver biopsy revealed markedly reduced complex I + III and II + III activities that were restored by addition of $\mathrm{CoQ}_{10}$ to the liver homogenate indicating ubiquinone deficiency. However, $\mathrm{CoQ}_{10}$ level and the molecular defect in this patient are unknown [15]. 
In 2001, Musumeci et al. described the most common phenotype associated with $\mathrm{CoQ}_{10}$ deficiency in muscle, characterized by childhood-onset cerebellar ataxia and atrophy variably associated with neuropathy, seizures, mental retardation, muscle weakness, hypogonadism, and low levels of $\mathrm{CoQ}_{10}$ in fibroblasts [5,6,16-19]. Some patients with juvenile-onset cerebellar ataxia carry mutations in $A D C K 3 / C A B C 1[5,6]$. Mutations in this gene have been recently found in additional patients with cerebellar ataxia, cerebellar atrophy, exercise intolerance, dystonia, and mild cognitive impairment. However, the level of $\mathrm{CoQ}_{10}$ in muscle and fibroblasts from these patients was not mentioned [20].

Supplementation with $\mathrm{CoQ}_{10}$ was associated with mild, subjective, clinical improvement in patients with cerebellar ataxia associated with mutations in $A D C K 3 / C A B C 1$ [5,6]. More recently, Pineda et al. assessed the clinical outcome in 14 patients with cerebellar ataxia with and without documented $\mathrm{CoQ}_{10}$ deficiency in muscle and/or fibroblasts and unknown molecular defect and observed that all patients with $\mathrm{CoQ}_{10}$ deficiency responded to the therapy [21].

\section{Secondary $\operatorname{CoQ}_{10}$ deficiencies}

In three of the five patients originally described by Musumeci in 2001, secondary $\mathrm{CoQ}_{10}$ deficiency has been found to result from a stop codon mutation in the APTX gene encoding aprataxin $[16,22,23]$, a protein involved in double-stranded DNA repair known to cause ataxia-oculomotor-apraxia 1 (AOA1) $[24,25]$. In these patients, $\mathrm{CoQ}_{10}$ deficiency was not correlated with disease duration, severity, or progression or with biologic measures, indicating that $\mathrm{CoQ}_{10}$ deficiency is not the primary or the only cause of neurological decline in AOA1. Nevertheless, three patients improved considerably after $\mathrm{CoQ}_{10}$ supplementation [22].

Lalani and Horvath described a pure myopathic form of $\mathrm{CoQ}_{10}$ deficiency, with lipid storage myopathy and respiratory chain dysfunction [26,27]. In 2007, Gempel and coworkers [28] found that the patients reported by Horvath and colleagues had mutations in the ETFDH gene encoding electron-transferring flavoprotein dehydrogenase, which previously had been associated with glutaric aciduria type II (multiple acyl-CoA dehydrogenase deficiency [MADD]). In that report, all seven patients from five families presented with exercise intolerance, fatigue, proximal myopathy, and high serum creatine kinase (CK). Muscle histology showed lipid storage and subtle signs of mitochondrial myopathy. All of the patients with pure myopathy showed dramatic improvements after $\mathrm{CoQ}_{10}$ supplementation [28]. In contrast, other studies reported patients with MADD and ETFDH mutations who had normal $\mathrm{CoQ}_{10}$ levels in muscle $[29,30]$.

Secondary $\mathrm{CoQ}_{10}$ deficiency with multisystemic infantile presentation has also been described in one patient with cardiofaciocutaneous syndrome due to a BRAF mutation [31].

Secondary $\mathrm{CoQ}_{10}$ deficiency in muscle has been reported in patients with a variety of mitochondrial diseases. In 1989, Zierz et al. described a patient with Kearns-Sayre syndrome and reduced $\mathrm{CoQ}_{10}$ level in plasma and muscle [32]. In 1991, Matsuoka et al. reported that levels of $\mathrm{CoQ}_{10}$ in muscle from 25 patients with mitochondrial encephalomyopathies, mostly carrying mtDNA mutations, were significantly lower than in controls [33]. Montero et al. in 2005 found just one patient with mild decrease in $\mathrm{CoQ}_{10}$ level in a group of nine patients with diagnosis of mitochondrial disease [34]. In 2009, the same group reported that a newborn girl with mtDNA depletion and $\mathrm{CoQ}_{10}$ deficiency in muscle and fibroblasts, without molecular defect in any gene, was known to be involved in mtDNA depletion syndrome, but mutation screening of genes required for $\mathrm{CoQ}_{10}$ biosynthesis was not performed [35]. In 2008, Miles et al. assessed $\mathrm{CoQ}_{10}$ muscle level in a large cohort of pediatric patients with possible or probable mitochondrial disease and found significantly 
decreased $\mathrm{CoQ}_{10}$ concentration in the probable defect group [36]. The most recent study is a multicenter analysis performed in 76 patients with heterogeneous mitochondrial phenotypes, which showed a high proportion of patients with $\mathrm{CoQ}_{10}$ deficiency, including patients with isolated PEO and PEO associated with myopathy, patients with multisystemic disease and/ with encephalomyopathy [37]. Thus, coenzyme $\mathrm{Q}_{10}$ deficiency appears to be a relatively common finding in mitochondrial disorders and is likely to benefit from exogenous supplementation; large-scale randomized clinical trials to evaluate this treatment options are now underway [38].

There is growing evidence of acquired $\mathrm{CoQ}_{10}$ deficiencies; however, in these conditions, $\mathrm{CoQ}_{10}$ level was measured and found low in plasma and/or serum [39]. In contrast, there are few reports of $\mathrm{CoQ}_{10}$ measurement in tissues, but one report showed evidence of low $\mathrm{CoQ}_{10}$ in the muscle of a sub-group of children with food intolerance and allergies [40].

\section{In vitro studies of primary $\mathrm{CoQ}_{10}$ deficiencies}

The disparate phenotype and responses to $\mathrm{CoQ}_{10}$ supplementation suggest differences in the pathomechanisms of $\mathrm{CoQ}_{10}$ deficiencies or in the pharmacokinetics of $\mathrm{CoQ}_{10}$ supplementation. To address these issues, the consequence of $\mathrm{CoQ}_{10}$ deficiency on mitochondrial bioenergetics, oxidative stress, and antioxidant defenses in tissues and cells from patients with $\mathrm{CoQ}_{10}$ deficiencies and the effects of $\mathrm{CoQ}_{10}$ supplementation have been investigated.

Initial studies of cultured fibroblasts from two siblings with infantile-onset $\mathrm{CoQ}_{10}$ deficiency showed mild respiratory chain defects but no evidence of increased superoxide anions, lipid peroxidation, or apoptosis-mediated cell death [41].

Lopez-Martin et al. showed that $C O Q 2$ mutant fibroblasts require uridine to maintain growth and proposed that deficiency of $\mathrm{CoQ}_{10}$ caused a defect in de novo pyrimidine biosynthesis because of the dependence of dihydro-orotate dehydrogenase on ubiquinol [42].

In the same two cell lines carrying $C O Q 2$ mutations and in two other cell lines from patients with $\mathrm{CoQ}_{10}$ deficiency with unknown molecular defects, Rodriguez-Hernandez et al. observed increased levels of lysosomal markers as well as enhanced expression of transcriptional and translational levels of autophagic genes [43]. Because inhibition of autophagy resulted in apoptotic cell death, the authors suggested that autophagy is a protective mechanism involved in the degradation of dysfunctional mitochondria.

Our initial studies in cultured skin fibroblasts harboring COQ2 and PDSS2 mutations suggested that defects in the first two committed steps of the $\mathrm{CoQ}_{10}$ biosynthetic pathway produce different biochemical alterations. PDSS2 mutant fibroblasts have $12 \% \mathrm{CoQ}_{10}$ content and $28 \%$ residual CII+III activity relative to control cells with markedly reduced ATP synthesis, but do not show increased ROS production, signs of oxidative stress, or increased antioxidant defense markers. In contrast, COQ2 mutant fibroblasts have 30\% $\mathrm{CoQ}_{10}$ content and $48 \%$ residual CII+III activity with mild defects of ATP synthesis and show significantly increased ROS production as well as oxidation of lipids and proteins [44]. We extended our studies to other patients' cell lines, with variable degrees of $\mathrm{CoQ}_{10}$ deficiency due to different molecular defects, including mutations in $C O Q 2$ [3], ADCK3/ $C A B C 1$ [4,5], and $C O Q^{9}$ [7], and we have observed a correlation between levels of $\mathrm{CoQ}_{10}$ and ROS production: $10-15 \%$ or $>60 \%$ residual $\mathrm{CoQ}_{10}$ content is not associated with significant ROS production, whereas $30-50 \%$ residual $\mathrm{CoQ}_{10}$ content is associated with maximal increases in ROS production and cell death [45]. These studies confirm that varying degrees of $\mathrm{CoQ}_{10}$ variably impair ATP synthesis and induce oxidative stress. In the same cell lines with mutations in $P D S S 2, C O Q 2$, and $C O Q 9$, we have evaluated the efficacy 
of $\mathrm{CoQ}_{10}$ supplementation in normalizing the bioenergetic status and the oxidative balance, comparing it with the efficacies of short-tail ubiquinone analogs (idebenone and $\mathrm{CoQ}_{2}$ ), which are less lipophilic, and vitamin C, a hydrophilic antioxidant [46]. We observed that after $24 \mathrm{H}$ of $5 \mu \mathrm{M} \mathrm{CoQ}_{10}$ supplementation (the approximate concentration reached in the plasma of patients treated with high doses of oral supplementation of $\mathrm{CoQ}_{10}$ ), cellular $\mathrm{CoQ}_{10}$ levels increased dramatically and that all four compounds significantly reduced superoxide anion levels and cell death in mutant fibroblasts with oxidative stress. However, after $24 \mathrm{~h}$ of $\mathrm{CoQ}_{10}$ treatment, none of the cell lines showed significant improvement in ATP levels or in ATP/ADP ratios, which are markers of respiratory chain function. In marked contrast to treatment for $24 \mathrm{~h}$ of $\mathrm{CoQ}_{10}$, incubation of ubiquinone-deficient fibroblasts for 1 week with $5 \mu \mathrm{M} \mathrm{CoQ}_{10}$ (but not short-tail ubiquinone analogs and vitamin C) increased ATP levels and ATP/ADP ratios significantly [46]. These results indicate that the pharmacokinetic constraints of $\mathrm{CoQ}_{10}$ in reaching the mitochondrial respiratory chain and the dose of $\mathrm{CoQ}_{10}$ are key limiting factors in determining its efficacy in $\mathrm{CoQ}_{10}$-deficient patients.

\section{Conclusions}

$\mathrm{CoQ}_{10}$ deficiencies are clinically and genetically heterogeneous diseases that can occur due to defects of ubiquinone biosynthesis (primary deficiencies) or due to other causes (secondary deficiencies). Diagnosis of $\mathrm{CoQ}_{10}$ deficiency is most reliably made by measuring levels in muscle, fibroblasts, or both, but not plasma as circulating levels are influenced by dietary intake. Because both forms may improve with $\mathrm{CoQ}_{10}$ supplementation early diagnosis is important. In vitro studies have revealed that $\mathrm{CoQ}_{10}$ deficiency leads to diverse biochemical consequences that variably contribute to cell death. Future studies are likely to identify new causes and to provide new insights into the pathogenesis and treatment of $\mathrm{CoQ}_{10}$ deficiencies.

\section{Acknowledgments}

This work was supported by NIH grants R01HD057543 (cofunded by NICHD and the NIH Office of Dietary Supplement) and K23 HD065871. In addition, the authors have been supported by grants from the NIH (R01HD056103, RC1 NS070232, and P01 HD032062), Muscular Dystrophy Association (MDA), and by the Marriott Mitochondrial Disorder Clinical Research Fund (MMDCRF).

\section{References}

1. Lopez LC, Schuelke M, Quinzii CM, Kanki T, Rodenburg RJ, Naini A, DiMauro S, Hirano M. Leigh syndrome with nephropathy and $\mathrm{CoQ}_{10}$ deficiency due to decaprenyl diphosphate synthase subunit 2 (PDSS2) mutations. Am J Hum Genet. 2006; 79:1125-1129. [PubMed: 17186472]

2. Quinzii C, Naini A, Salviati L, Trevisson E, Navas P, DiMauro S, Hirano M. A mutation in parahydroxybenzoate-polyprenyl transferase (COQ2) causes primary coenzyme $\mathrm{Q}_{10}$ deficiency. Am J Hum Genet. 2006; 78:345-349. [PubMed: 16400613]

3. Diomedi-Camassei F, Di Giandomenico S, Santorelli FM, Caridi G, Piemonte F, Montini G, Ghiggeri GM, Murer L, Barisoni L, Pastore A, Muda AO, Valente ML, Bertini E, Emma F. COQ2 nephropathy: a newly described inherited mitochondriopathy with primary renal involvement. J Am Soc Nephrol. 2007; 18:2773-2780. [PubMed: 17855635]

4. Mollet J, Giurgea I, Schlemmer D, Dallner G, Chretien D, Delahodde A, Bacq D, de Lonlay P, Munnich A, Rötig A. Prenyldiphosphate synthase, subunit 1 (PDSS1) and OH-benzoate polyprenyltransferase (COQ2) mutations in ubiquinone deficiency and oxidative phosphorylation disorders. J Clin Invest. 2007; 117:765-772. [PubMed: 17332895]

5. Lagier-Tourenne C, Tazir M, Lopez LC, Quinzii CM, Assoum M, Drouot N, Busso C, Makri S, AliPacha L, Benhassine T, Anheim M, Lynch DR, Thibault C, Plewniak F, Bianchetti L, Tranchant C, Poch O, DiMauro S, Mandel JL, Barros MH, Hirano M, Koenig M. ADCK3, an ancestral kinase, is 
mutated in a form of recessive ataxia associated with coenzyme $\mathrm{Q}_{10}$ deficiency. Am J Hum Genet. 2008; 82:661-672. [PubMed: 18319074]

6. Mollet J, Delahodde A, Serre V, Chretien D, Schlemmer D, Lombes A, Boddaert N, Desguerre I, de Lonlay P, de Baulny HO, Munnich A, Rötig A. CABC1 gene mutations cause ubiquinone deficiency with cerebellar ataxia and seizures. Am J Hum Genet. 2008; 82:623-630. [PubMed: 18319072]

7. Duncan AJ, Bitner-Glindzicz M, Meunier B, Costello H, Hargreaves IP, Lopez LC, Hirano M, Quinzii CM, Sadowski MI, Hardy J, Singleton A, Clayton PT, Rahman S. A nonsense mutation in COQ9 causes autosomal-recessive neonatal-onset primary coenzyme $\mathrm{Q}_{10}$ deficiency: a potentially treatable form of mitochondrial disease. Am J Hum Genet. 2009; 84:558-566. [PubMed: 19375058]

8. Ogasahara S, Engel AG, Frens D, Mack D. Muscle coenzyme Q deficiency in familial mitochondrial encephalomyopathy. Proc Natl Acad Sci USA. 1989; 86:2379-2382. [PubMed: 2928337]

9. Sobreira C, Hirano M, Shanske S, Keller RK, Haller RG, Davidson E, Santorelli FM, Miranda AF, Bonilla E, Mojon DS, Barreira AA, King MP, DiMauro S. Mitochondrial encephalomyopathy with coenzyme $Q_{10}$ deficiency. Neurology. 1997; 48:1238-1243. [PubMed: 9153450]

10. Boitier E, Degoul F, Desguerre I, Charpentier C, François D, Ponsot G, Diry M, Rustin P, Marsac C. A case of mitochondrial encephalomyopathy associated with a muscle coenzyme $\mathrm{Q}_{10}$ deficiency. J Neurol Sci. 1998; 156:41-46. [PubMed: 9559985]

11. Di Giovanni S, Mirabella M, Spinazzola A, Crociani P, Silvestri G, Broccolini A, Tonali P, Di Mauro S, Servidei S. Coenzyme $\mathrm{Q}_{10}$ reverses pathological phenotype and reduces apoptosis in familial CoQ 10 deficiency. Neurology. 2001; 57:515-518. [PubMed: 11502923]

12. Aure K, Benoist JF, Ogier de Baulny H, Romero NB, Rigal O, Lombes A. Progression despite replacement of a myopathic form of coenzyme $Q_{10}$ defect. Neurology. 2004; 63:727-729. [PubMed: 15326254]

13. Salviati L, Sacconi S, Murer L, Zaccello G, Franceschini L, Laverda AM, Basso G, Quinzii CM, Angelini C, Hirano M, Naini A, Navas P, DiMauro S, Montini G. Infantile encephalomyopathy and nephropathy with $\mathrm{CoQ}_{10}$ deficiency: a $\mathrm{CoQ}_{10}$-responsive condition. Neurology. 2005; 65:606-608. [PubMed: 16116126]

14. Montini G, Malaventura C, Salviati L. Early coenzyme $Q_{10}$ supplementation in primary coenzyme Q10 deficiency. N Engl J Med. 2008; 358:2849-2850. [PubMed: 18579827]

15. Leshinsky-Silver E, Levine A, Nissenkorn A, Barash V, Perach M, Buzhaker E, Shahmurov M, Polak-Charcon S, Lev D, Lerman-Sagie T. Neonatal liver failure and Leigh syndrome possibly due to CoQ-responsive OXPHOS deficiency. Mol Genet Metab. 2003; 79:288-293. [PubMed: 12948744]

16. Musumeci O, Naini A, Slonim AE, Skavin N, Hadjigeorgiou GL, Krawiecki N, Weissman BM, Tsao CY, Mendell JR, Shanske S, De Vivo DC, Hirano M, DiMauro S. Familial cerebellar ataxia with muscle coenzyme $\mathrm{Q}_{10}$ deficiency. Neurology. 2001; 56:849-855. [PubMed: 11294920]

17. Lamperti C, Naini A, Hirano M, De Vivo DC, Bertini E, Servidei S, Valeriani M, Lynch D, Banwell B, Berg M, Dubrovsky T, Chiriboga C, Angelini C, Pegoraro E, DiMauro S. Cerebellar ataxia and coenzyme $\mathrm{Q}_{10}$ deficiency. Neurology. 2003; 60:1206-1208. [PubMed: 12682339]

18. Gironi M, Lamperti C, Nemni R, Moggio M, Comi G, Guerini FR, Ferrante P, Canal N, Naini A, Bresolin N, DiMauro S. Late-onset cerebellar ataxia with hypogonadism and muscle coenzyme Q10 deficiency. Neurology. 2004; 62:818-820. [PubMed: 15007142]

19. Artuch R, Brea-Calvo G, Briones P, Aracil A, Galvan M, Espinos C, Corral J, Volpini V, Ribes A, Andreu AL, Palau F, Sanchez-Alcazar JA, Navas P, Pineda M. Cerebellar ataxia with coenzyme $\mathrm{Q}(10)$ deficiency: diagnosis and follow-up after coenzyme Q(10) supplementation. J Neurol Sci. 2006; 246:153-158. [PubMed: 16677673]

20. Gerards M, van den Bosch B, Calis C, Schoonderwoerd K, van Engelen K, Tijssen M, de Coo R, van der Kooi A, Smeets H. Nonsense mutations in CABC1/ADCK3 cause progressive cerebellar ataxia and atrophy. Mitochondrion. 2010; 10:510-515. [PubMed: 20580948]

21. Pineda M, Montero R, Aracil A, O’Callaghan MM, Mas A, Espinos C, Martinez-Rubio D, Palau F, Navas P, Briones P, Artuch R. Coenzyme Q(10)-responsive ataxia: 2-year-treatment follow-up. Mov Disord. 2010; 25:1262-1268. [PubMed: 20629161] 
22. Quinzii CM, Kattah AG, Naini A, Akman HO, Mootha VK, DiMauro S, Hirano M. Coenzyme Q deficiency and cerebellar ataxia associated with an aprataxin mutation. Neurology. 2005; 64:539541. [PubMed: 15699391]

23. Le Ber I, Dubourg O, Benoist JF, Jardel C, Mochel F, Koenig M, Brice A, Lombes A, Durr A. Muscle coenzyme $\mathrm{Q}_{10}$ deficiencies in ataxia with oculomotor apraxia 1. Neurology. 2007; 68:295-297. [PubMed: 17242337]

24. Date H, Onodera O, Tanaka H, Iwabuchi K, Uekawa K, Igarashi S, Koike R, Hiroi T, Yuasa T, Awaya Y, Sakai T, Takahashi T, Nagatomo H, Sekijima Y, Kawachi I, Takiyama Y, Nishizawa M, Fukuhara N, Saito K, Sugano S, Tsuji S. Early-onset ataxia with ocular motor apraxia and hypoalbuminemia is caused by mutations in a new HIT superfamily gene. Nat Genet. 2001; 29:184-188. [PubMed: 11586299]

25. Moreira MC, Barbot C, Tachi N, Kozuka N, Uchida E, Gibson T, Mendonca P, Costa M, Barros J, Yanagisawa T, Watanabe M, Ikeda Y, Aoki M, Nagata T, Coutinho P, Sequeiros J, Koenig M. The gene mutated in ataxia-ocular apraxia 1 encodes the new HIT/Zn-finger protein aprataxin. Nat Genet. 2001; 29:189-193. [PubMed: 11586300]

26. Lalani SR, Vladutiu GD, Plunkett K, Lotze TE, Adesina AM, Scaglia F. Isolated mitochondrial myopathy associated with muscle coenzyme $\mathrm{Q}_{10}$ deficiency. Arch Neurol. 2005; 62:317-320. [PubMed: 15710863]

27. Horvath R, Schneiderat P, Schoser BG, Gempel K, Neuen-Jacob E, Ploger H, Muller-Hocker J, Pongratz DE, Naini A, DiMauro S, Lochmuller H. Coenzyme $\mathrm{Q}_{10}$ deficiency and isolated myopathy. Neurology. 2006; 66:253-255. [PubMed: 16434667]

28. Gempel K, Topaloglu H, Talim B, Schneiderat P, Schoser BG, Hans VH, Palmafy B, Kale G, Tokatli A, Quinzii C, Hirano M, Naini A, Dimauro S, Prokisch H, Lochmuller H, Horvath R. The myopathic form of coenzyme $\mathrm{Q}_{10}$ deficiency is caused by mutations in the electron-transferringflavoprotein dehydrogenase (ETFDH) gene. Brain. 2007; 130:2037-2044. [PubMed: 17412732]

29. Liang WC, Ohkuma A, Hayashi YK, Lopez LC, Hirano M, Nonaka I, Noguchi S, Chen LH, Jong YJ, Nishino I. ETFDH mutations, $\mathrm{CoQ}_{10}$ levels, and respiratory chain activities in patients with riboflavin-responsive multiple acyl-CoA dehydrogenase deficiency. Neuromuscul Disord. 2009; 19:212-216. [PubMed: 19249206]

30. Ohkuma A, Noguchi S, Sugie H, Malicdan MC, Fukuda T, Shimazu K, Lopez LC, Hiranom M, Hayashi YK, Nonaka I, Nishino I. Clinical and genetic analysis of lipid storage myopathies. Muscle Nerve. 2009; 39:333-342. [PubMed: 19208393]

31. Aeby A, Sznajer Y, Cave H, Rebuffat E, Van Coster R, Rigal O, Van Bogaert P. Cardiofaciocutaneous (CFC) syndrome associated with muscular coenzyme $\mathrm{Q}_{10}$ deficiency. J Inherit Metab Dis. 2007; 30:827. [PubMed: 17703371]

32. Zierz S, Jahns G, Jerusalem F. Coenzyme Q in serum and muscle of 5 patients with Kearns-Sayre syndrome and 12 patients with ophthalmoplegia plus. J Neurol. 1989; 236:97-101. [PubMed: 2709060]

33. Matsuoka T, Maeda H, Goto Y, Nonaka I. Muscle coenzyme $\mathrm{Q}_{10}$ in mitochondrial encephalomyopathies. Neuromuscul Disord. 1991; 1:443-447. [PubMed: 1822356]

34. Montero R, Artuch R, Briones P, Nascimento A, Garcia-Cazorla A, Vilaseca MA, SanchezAlcazar JA, Navas P, Montoya J, Pineda M. Muscle coenzyme $\mathrm{Q}_{10}$ concentrations in patients with probable and definite diagnosis of respiratory chain disorders. Biofactors. 2005; 25:109-115. [PubMed: 16873935]

35. Montero R, Sanchez-Alcazar JA, Briones P, Navarro-Sastre A, Gallardo E, Bornstein B, HerreroMartin D, Rivera H, Martin MA, Marti R, Garcia-Cazorla A, Montoya J, Navas P, Artuch R. Coenzyme $\mathrm{Q}_{10}$ deficiency associated with a mitochondrial DNA depletion syndrome: a case report. Clin Biochem. 2009; 42:742-745. [PubMed: 19094978]

36. Miles MV, Miles L, Tang PH, Horn PS, Steele PE, DeGrauw AJ, Wong BL, Bove KE. Systematic evaluation of muscle coenzyme $\mathrm{Q}_{10}$ content in children with mitochondrial respiratory chain enzyme deficiencies. Mitochondrion. 2008; 8:170-180. [PubMed: 18313367]

37. Sacconi S, Trevisson E, Salviati L, Ayme S, Rigal O, Redondo AG, Mancuso M, Siciliano G, Tonin P, Angelini C, Aure K, Lombes A, Desnuelle C. Coenzyme $\mathrm{Q}_{10}$ is frequently reduced in muscle of patients with mitochondrial myopathy. Neuromuscul Disord. 2010; 20:44-48. [PubMed: 19945282] 
38. Hassani A, Horvath R, Chinnery PF. Mitochondrial myopathies: developments in treatment. Curr Opin Neurol. 2010; 23:459-465. [PubMed: 20651591]

39. Rundek T, Naini A, Sacco R, Coates K, DiMauro S. Atorvastatin decreases the coenzyme $\mathrm{Q}_{10}$ level in the blood of patients at risk for cardiovascular disease and stroke. Arch Neurol. 2004; 61:889-892. [PubMed: 15210526]

40. Miles MV, Putnam PE, Miles L, Tang PH, DeGrauw AJ, Wong BL, Horn PS, Foote HL, Rothenberg ME. Acquired coenzyme $\mathrm{Q}_{10}$ deficiency in children with recurrent food intolerance and allergies. Mitochondrion. 2011; 11:127-135. [PubMed: 20817046]

41. Geromel V, Kadhom N, Ceballos-Picot I, Chretien D, Munnich A, Rötig A, Rustin P. Human cultured skin fibroblasts survive profound inherited ubiquinone depletion. Free Radic Res. 2001; 35:11-21. [PubMed: 11697113]

42. Lopez-Martin JM, Salviati L, Trevisson E, Montini G, DiMauro S, Quinzii C, Hirano M, Rodriguez-Hernandez A, Cordero MD, Sanchez-Alcazar JA, Santos-Ocana C, Navas P. Missense mutation of the COQ2 gene causes defects of bioenergetics and de novo pyrimidine synthesis. Hum Mol Genet. 2007; 16:1091-1097. [PubMed: 17374725]

43. Rodríguez-Hernández A, Cordero MD, Salviati L, Artuch R, Pineda M, Briones P, Gómez Izquierdo L, Cotán D, Navas P, Sánchez-Alcázar JA. Coenzyme Q deficiency triggers mitochondria degradation by mitophagy. Autophagy. 2009; 5:19-32. [PubMed: 19115482]

44. Quinzii CM, Lopez LC, Von-Moltke J, Naini A, Krishna S, Schuelke M, Salviati L, Navas P, DiMauro S, Hirano M. Respiratory chain dysfunction and oxidative stress correlate with severity of primary $\mathrm{CoQ}_{10}$ deficiency. FASEB J. 2008; 22:1874-1885. [PubMed: 18230681]

45. Quinzii CM, Lopez LC, Gilkerson RW, Dorado B, Coku J, Naini AB, Lagier-Tourenne C, Schuelke M, Salviati L, Carrozzo R, Santorelli F, Rahman S, Tazir M, Koenig M, DiMauro S, Hirano M. Reactive oxygen species, oxidative stress, and cell death correlate with level of $\mathrm{CoQ}_{10}$ deficiency. FASEB J. 2010; 24:3733-3743. [PubMed: 20495179]

46. López LC, Quinzii C, Area E, Naini A, Rahman S, Schuelke M, Salviati L, Navas P, DiMauro S, Hirano $\mathrm{M}$. Treatment of $\mathrm{CoQ}_{10}$ deficient fibroblasts with ubiquinone, analogs, and vitamin $\mathrm{C}$ : time- and compound-dependent effects on bioenergetic and oxidative stress status. PloS One. 2010; 5:e11897. [PubMed: 20689595] 